\title{
LABORATÓRIO EFÊMERO GUAJA SAPUCAÍ: WORKSHOP DE FABRICAÇÃO DIGITAL1
}

\author{
Marcos Mascarenhas Franchini Oliveira²
}

DOI: 10.5752/P.2316-1752.2018v25n37p220

\section{Resumo}

O presente trabalho tem como objetivo discutir alternativas para a formação de profissionais do campo da construção civil, que permitem o trânsito entre diferentes conhecimentos e que, de fato, propiciam o desenvolvimento de uma transdisciplinaridade na concepção de projetos, criatividades e aplicações práticas dos jovens e futuros profissionais. Pretende-se descrever os fundamentos da era digital, suas práticas de produção e viabilidade como estímulo - e avanço - do aprender-fazendo, eixo central deste artigo, que é abordado a partir de uma experiência de um workshop de fabricação digital.

Palavras-chave: Ensino-aprendizagem na construção. Experimentação. Transdisciplinaridade.

1. Este artigo toma por base um dos capítulos da dissertação de mestrado de Marcos M. Franchini, no Programa de Pós-Graduação em Ciências da Construção Metálica (MECOM) da Universidade Federal de Ouro Preto (UFOP), sob orientação de Ernani Araújo e co-orientação de Tito Flávio Aguiar.

2. Arquiteto Urbanista pela PUC Minas, mestre em Ciências da Construção Metálica pela UFOP. E-mail: contato@mfranchini.com 
EPHEMERAL LAB GUAJA SAPUCAI: DIGITAL MANUFACTURING WORKSHOP

\section{5}

\section{Abstract}

The present work aims to discuss alternatives in the teaching of professionals in the field of construction that allow the transit between different knowledge and that, in fact, provide development of a transdisciplinarity in the conception of projects, creativities and practical applications of the young and future professionals. It is intended to describe the fundamentals of the digital age, their production and sustainability practices as a stimulus - and advance - of learning by doing, the central axis of this article which is approached from an experience of a digital manufacturing workshop.

Keywords: Daylight. Ceiling height Environmental confort.

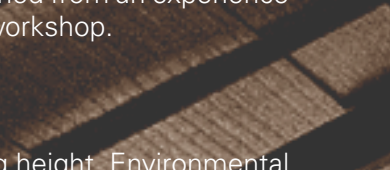

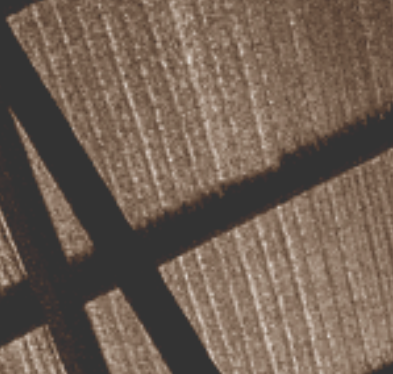

LABORATORIO EFÉMERO GUAJA SAPUCAÝTA LLER DE FABRICACIÓN DIGITAL

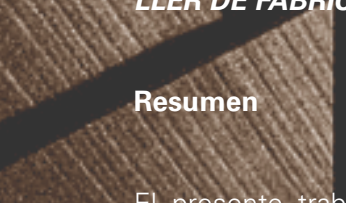

El presente trabajo tiene como objetivo discutir alternativas en la enseñanza de profesionales del campo de la construcción civil que permiten el tránsito entre diferentes conocimientos y due de hecho, propician el desarrollo de una transdisciplinariedad en la concepción de proyectos, creatividades y aplicaciones prácticas de los jóvenes y futuros profesionales. Se pretende describir los fundamentos de la era digital, sus prácticas de producción y viabilidad como estímulo - y avance del aprendizaje-haciendo, ejercentral de este artículo que se aborda a partir de una experiencia de un taller de fabricación digital.

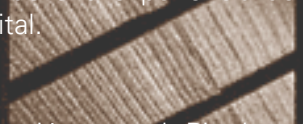

Palabras-claves: Iluminación natural Pie-derecho. Confort térmico.
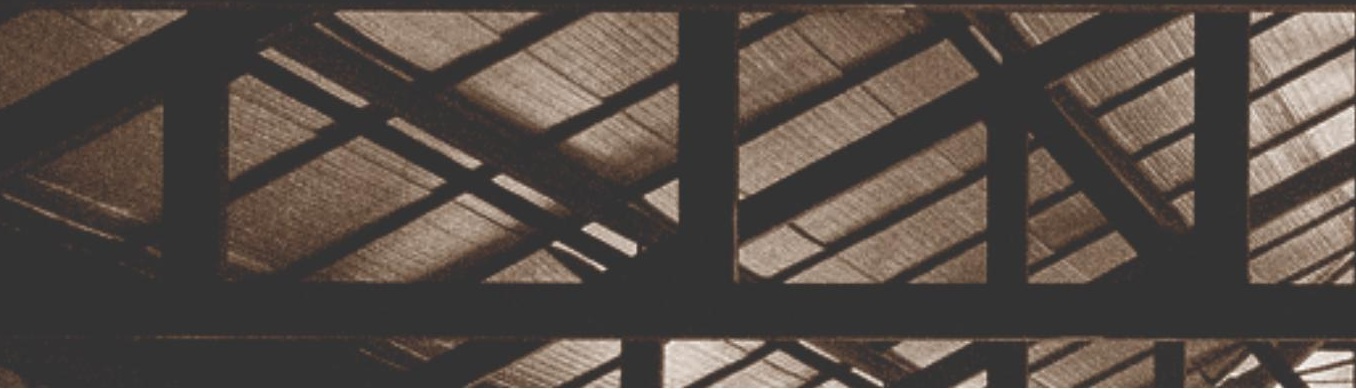
O presente artigo descreve, por meio de uma experiência pessoal do autor enquanto um dos orientadores, o workshop de fabricação digital "Laboratório Efêmero", a fim de reconhecer aproximações com a dimensão prática da arquitetura e averiguar o aprendizado a partir do fazer. Como efeito colateral, faz-se necessário assimilar e refletir sobre os conceitos que integram o contexto da era digital.

Segundo Montaner (2001, p.127 apud ARCIPRESTE, 2012 p.129), dá-se um novo enfoque para o desenho das soluções arquitetônicas e de intervenção urbanística na busca de alternativas para o cenário cultural, econômico e tecnológico vigente. O espaço de ensino, ao possuir certa independência em relação ao mercado e à cadeia produtiva, torna-se lugar de crítica e reflexão dos diversos conflitos que são presentes nos dias atuais. Nesse arranjo, apresentam-se alternativas e experimentos pedagógicos que buscam responder às questões socioculturais de forma mais abrangente (ARCIPRESTE, 2012, p. 131).

Se essas práticas têm o objetivo de ampliar as percepções do usuário para apropriação e construção de espaços, elas dão ênfase à diversidade ao estabelecer critérios e métodos colaborativos no desenvolvimento de projetos que envolvem os usuários como participantes e coautores (ARClPRESTE, 2012, p. 143). 


\section{Maker innovation e Open design}

Atualmente, os processos alternativos de manufatura são alinhados com os fundamentos da era digital (colaboração, compartilhamento, open, co-design) e suas práticas de produção (fabricação digital, atitudes do it yourself aplicadas ao processo), fazendo com que alguns autores adotem o termo "Terceira Revolução Industrial" ou "Nova Revolução Industrial" para conceituar esse contexto (RIFIKIN; ANDERSON apud NEVES, 2014, p.39).

De acordo com Chris Anderson (2012 apud NEVES, 2014, p.42), que analisa as revoluções industriais de acordo com os marcos tecnológicos e seus impactos na sociedade, a "Primeira Revolução Industrial" é representada pela invenção do tear mecânico, o aumento da qualidade e expectativa de vida e o crescimento das cidades. A "Segunda Revolução Industrial" é marcada pelo desenvolvimento do Fordismo nas linhas de produção e montagem e, dessa forma, a separação entre o pensar e o fazer. $\mathrm{O}$ autor atribui ao termo "Nova Revolução Industrial" a relação da criação do computador e da internet com a possibilidade do fazer pelo pensar. Desse modo, o sistema produtivo que, até então, era pensado em partes passa a operar de uma maneira conectada em que o designer pode atuar de forma global desde a criação de um objeto até sua entrega ao usuário que também pode assumir outros papéis nesse processo. 
Segundo Heloisa Neves (2014), a inovação na indústria reside na maior acessibilidade das pessoas para fabricação de suas ideias, seja diretamente de suas casas, de um espaço coletivo equipado (os chamados makerspaces) ou mesmo por meio de plataformas online. Essa mudança de atitude faz com que o potencial das impressoras 3D, que já existem há algum tempo, seja mais bem explorado, transformando a maneira de se produzir; enquanto isoladas, essas máquinas continuam a produzir cópias do que já é feito pela indústria e pouco contribuem para um impacto revolucionário.

Nos dias atuais, uma única pessoa ou um grupo pequeno pode ser considerado um público-alvo - os modelos financeiros e produtivos, o desenvolvimento do mercado de nicho e a produção personalizada instituíram uma mudança profícua em que não se produz somente objetos iguais para um mercado que, na sua média, é igual. Nessa escala, Neves (2014, p.51) aponta que as máquinas de fabricação digital são ideais pelo seu funcionamento simplificado, sem a necessidade de uma produção inicial em grande quantidade.

Em 1974, o designer italiano Enzo Mari lançava o livro "Autoprogettazione?", uma referência na história do design contemporâneo. Posicionado em contraste com o formalismo na época, Enzo Mari sugere a democratização do de- 
sign, criando uma alternativa provocadora para o paradigma capitalista do consumo de massa. A proposta consistia no envio gratuito, sob demanda, de um conjunto de instruções para fabricação de dezenove peças de mobiliário, na forma de planos de corte e axonometrias, para serem autoproduzidos mediante um romaneio das peças que compõe o produto (Figura 1).

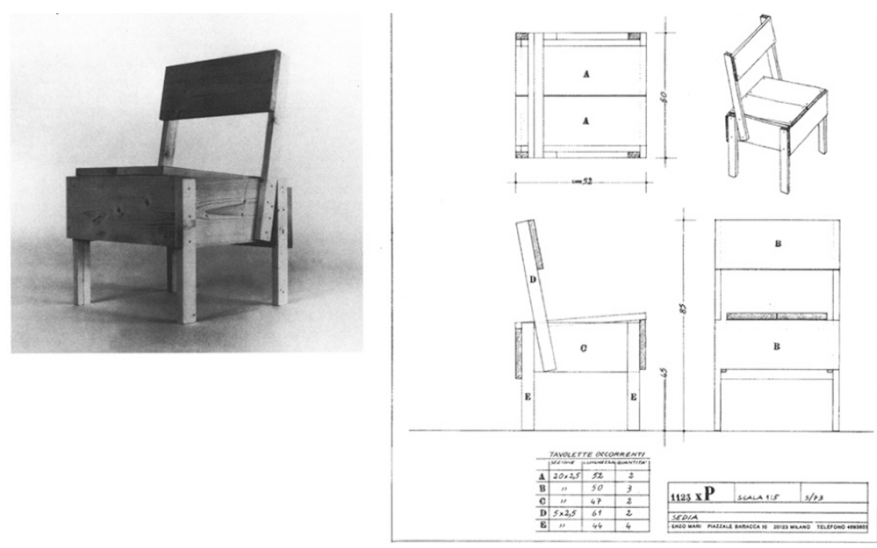

Figura 1| Autoprogettazione? página 5/73: Sedia Fonte: Mari (2002)

Apesar de idealizar uma fabricação de móveis mais humana e próxima do usuário de forma claramente didática, Mari conquistou inimizades daqueles que o acusavam de fazer 
seus clientes trabalhar em vez de agradá-los (NEVES, 2014, p. 76).

O problema da forma é sua busca pela sua essência. A forma corresponde ao significado de um objeto, e essa é a razão para um objeto ser construído e representa, se bem feito, a sua melhor qualidade. [...] A forma da natureza é sempre perfeita, o mundo natural não pode ser diferente do que ele é. Não se pode dizer que uma mão é feia ou bonita, uma mão sempre será precisa e justa. Seja de um pianista ou de uma criança. Design comunica conhecimento. (ARTEK, 2012, tradução nossa).

Os planos de Enzo Mari oferecem uma oportunidade para construir móveis com ferramentas simples e pouca expertise quando se trata de carpintaria. Ao fazê-lo, desenvolve-se um processo de aprendizagem e reflexão que exige o poder criativo individual e o design torna-se intimamente ligado à sustentabilidade e à responsabilidade social. Os reflexos do trabalho de Enzo Mari trouxeram consigo o princípio da horizontalidade entre profissional e usuário e da abertura do processo, bases fortíssimas para o conceito de Open Design que hoje vem se delineando.

Entende-se por Open Design o projeto de um objeto cuja documentação fonte é disponibilizada ao público para que qualquer pessoa possa estudar, modificar, distribuir, fabricar, prototipar e vender. Para isso, os arquivos de origem 
devem estar disponíveis com formatos de arquivo abertos e intercambiáveis, oferecendo às pessoas a liberdade de controlar sua tecnologia ao compartilhar conhecimento e incentivar o comércio por meio da troca aberta de projetos (NEVES, 2014, p. 128).

\section{Os Fab Labs como ambientes abertos de fa- bricação e inovação}

Na medida em que o Open Design se configura como um modelo alternativo de criação aberta, os ambientes físicos que interpretam esse conceito conformam espaços de invenção e intensa interação. Os Fab Labs proporcionam a possibilidade de qualquer pessoa fabricar objetos de forma personalizada sem a necessidade da participação de uma grande fábrica. Para Sara Griffits (2012 apud NEVES, 2014, p.130), os Fab Labs transformam-se em importantes locais para o desenvolvimento de competências sociais, base para o aparecimento da inovação (NEVES, 2014, p. 128).

Os Fab Labs são equipados com máquinas comandadas por computadores capazes de interpretar os arquivos de CAD/CAM (computer-aided design/computer-aided manufacturing), traduzindo as coordenadas $X, Y$ e $Z$ do modelo ou desenho digital em uma série de comandos de posição, velocidade, corte ou extrusão, reconhecíveis pela máquina. São, por princípio, espaços em que designers, artistas e 
estudantes podem empreender rapidamente seus projetos do nível conceitual ao protótipo a partir da experimentação e concretização (NEVES, 2014, p. 139).

A partir de um inventário desenvolvido pelo primeiro Fab Lab, que surgiu no Center for bits and atoms no Massachusetts Institute of Technology, Neves (2014) elabora um "kit básico" das máquinas indispensáveis para garantir a reprodução dos projetos ao redor do globo e a criação de processos de trabalho similares.

Um Fab Lab agrupa um conjunto de máquinas por comando numérico de nível profissional, porém de baixo custo, seguindo um padrão tipológico: uma máquina de corte a laser capaz de produzir estruturas 2D e 3D, uma máquina de corte de vinil que fabrica antenas e circuitos flexíveis, uma fresadora de alta resolução para fabricar circuitos impressos e moldes, uma outra maior para criar peças grandes. Há também componentes eletrônicos múltiplos, bem como ferramentas de programação associadas a micro controladores abertos, de baixo custo e eficientes. Estes dispositivos são controlados por meio de um software comum de concepção e fabricação assistida por computador. Os outros sistemas mais avançados, tais como as impressoras $3 D$, podem igualmente equipar os espaços. (NEVES, 2014, p. 132). 


\section{Opendesk e a cadeira Valoví}

Por meio da capacitação de designers e criadores independentes, estabelecendo uma rede global de oficinas de fabricação digital, a Opendesk se coloca como uma empresa singular que questiona a cadeia de produção e o modo pelo qual se consome objetos (OPENDESK, 2017).

A coleção de móveis Opendesk, concentrada inicialmente em espaços de trabalho, é composta inteiramente de projetos feitos em máquinas CNC (controle numérico computadorizado), de modo que o designer tenha que considerar novos conceitos e parâmetros a fim de garantir que seu projeto produza o mesmo produto, seja feito no Brasil, na Suécia ou no México.

Os designers escolhem seus próprios termos de licença, retêm todos os direitos sobre o seu trabalho e recebem uma taxa de design de $8 \%$ por cada peça fabricada comercialmente por um dos fabricantes mundiais licenciados pela Opendesk. Todavia, os arquivos CAD são gratuitos para serem baixados e podem ser produzidos, de forma independente, por qualquer pessoa, desde que não se faça uso comercial (OPENDESK, 2017).

As máquinas CNC são essencialmente grandes fresas controladas por computador que podem cortar formas em chapa de materiais diversos (geralmente madeira, mas 
também, metais e plásticos) seguindo um caminho que foi previamente programado em um computador. Esses caminhos (linhas) são desenhados em um software de CAD por um designer e, em seguida, convertidos nas trajetórias da ferramenta que informam à máquina $\mathrm{CNC}$ como interpretar cada linha (OPENDESK, 2017).

Destaca-se a cadeira Valoví, projetada pelo arquiteto brasileiro Denis Fuzii, baixada 13.232 vezes $^{4}$ em mais de 100 países por meio do site da Opendesk e que atualmente figura no Vitra Campus, em Weil am Rhein, entre peças icônicas de designers renomados. Uma vez que o arquivo é aberto, adaptações são possíveis para customização de cada usuário.

Cria-se, assim, um novo modelo de cadeias produtivas e interações comerciais, gerando empregos e aquecendo a economia local. Sem impostos de importação e exportação, sem transporte marítimo ou aéreo, sem fretes de longas distância, o movimento aquece a economia local e torna o mercado de mobiliário mais acessível a todos.

4. Para atualizações: https://www.opendesk.cc/studio-dlux/valovi-chair\#get-it-made. Acesso em: 11 nov. 2018 


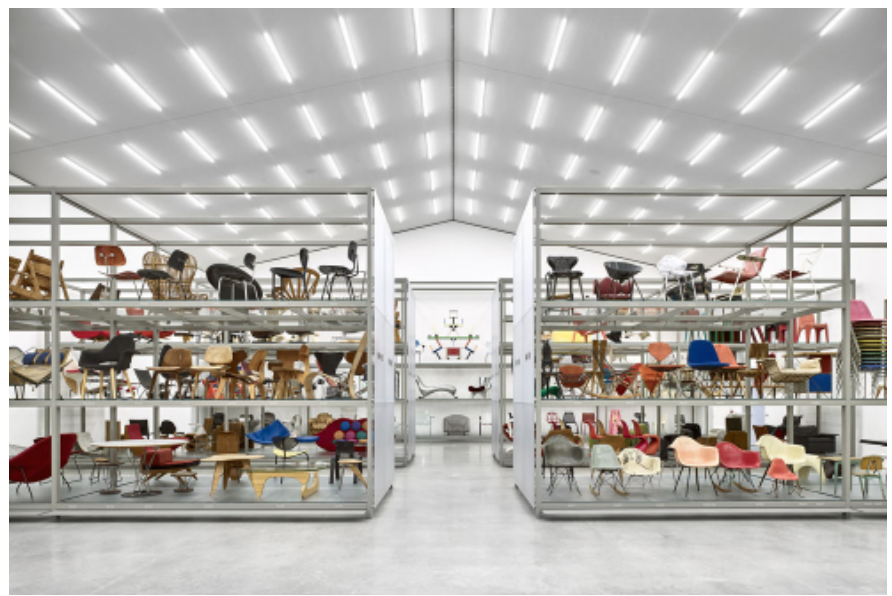

Figura 2 | Schaudepot.

Fonte: Opendesk (2017)

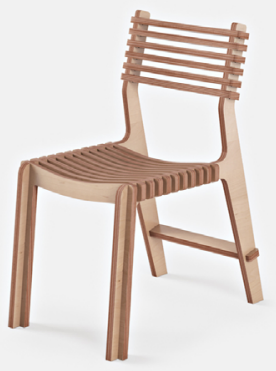

Figura 3 | Cadeira Valoví.

Fonte: Opendesk (2017) 


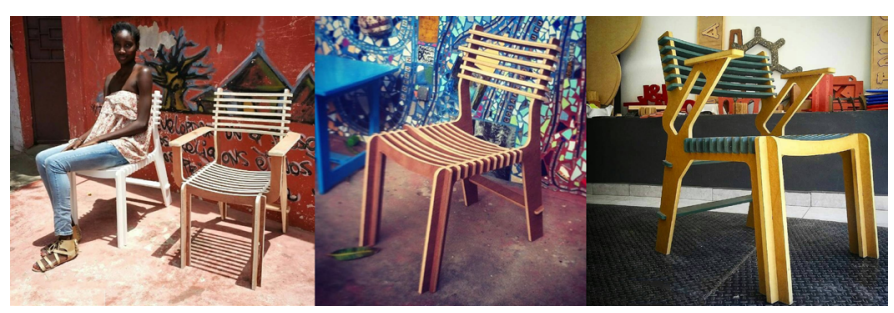

Figura 4 | Cadeira Valoví fabricada no Senegal e México Fonte: Studio dLux (2017)

\section{GUAJA Sapucaí}

\section{O processo de ocupação do espaço}

No ano de 2017, a mostra de arquitetura de interiores CASACOR Minas ocupou um importante edifício que integra o Conjunto Arquitetônico da Praça da Estação, região marcada pela forte efervescência urbana, cultural, política e gastronômica da cidade de Belo Horizonte.

O local, que funcionou como sede da extinta Rede Ferroviária Federal S/A (RFFSA) e está diretamente associado à criação da capital mineira, está localizado no limite entre a área do hipercentro e o bairro Floresta (Figura 5). Nos últimos anos, um processo de restauração vem sendo realizado no edifício, sob a supervisão do Instituto do Patrimônio Histórico e Artístico Nacional (IPHAN), para abrigar futuramente as instalações do Museu Ferroviário após mais de uma década fechado. 
O tempo deixa de concordar com a permanência e se relaciona com a efemeridade. Um modelo mais radical que toma forma mais experimental em uma arquitetura menos determinante, tendo a autoria de concepção do espaço diluída entre mais de 50 profissionais e estudantes dos campos de arquitetura e design, participantes dos workshops de fabricação digital e responsáveis pelo mobiliário que habitaram o sótão do casarão durante o evento.

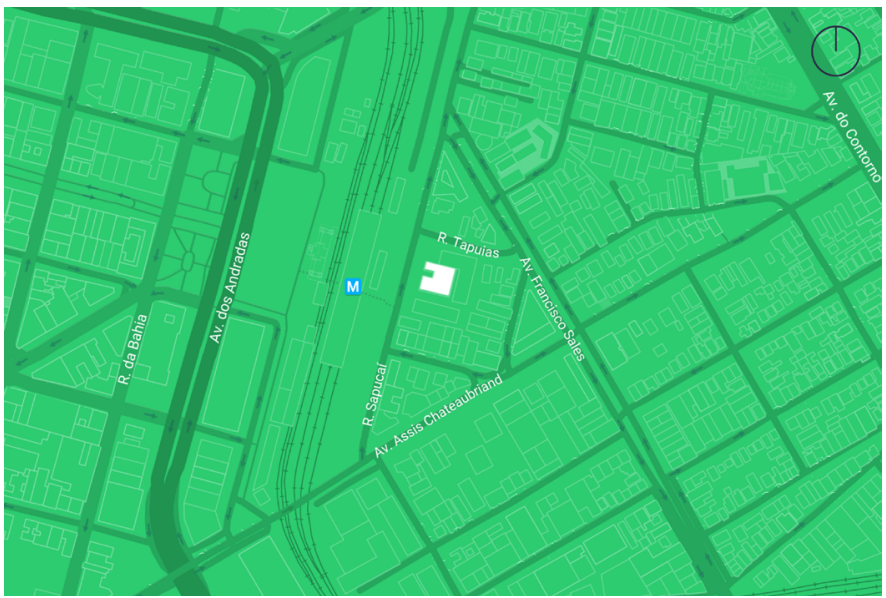

Figura 5 | Localização Casarão RFFSA.

Fonte: Elaborado pelo autor a partir de Googlemaps (2017) 


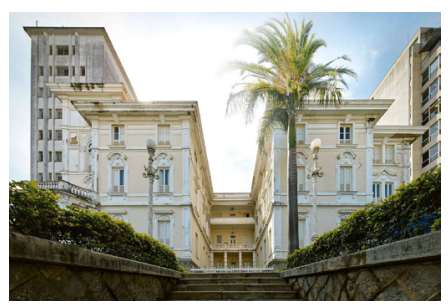

Figura 6 | Fachada Casarão RFFSA. Fonte: Jomar Bragança (2017)

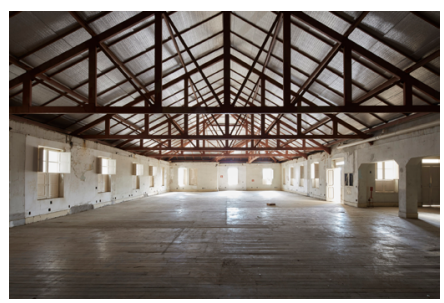

Figura 7 | Sotão Casarão RFFSA. Fonte: Jomar Bragança (2017)

Ao redimensionarem seu protagonismo, os arquitetos passam a motivadores de construções processuais em que 0 campo de atuação não é mais a exposição, mas ações subjetivas e coletivas que ensaiam vivências.

\section{O Laboratório Efêmero}

O GUAJA Sapucaí conformou um laboratório efêmero que reuniu todas as condições para que os processos de discussão e construção do espaço pudessem acontecer em sua integralidade. Além de participarem do processo de concepção do espaço, os participantes do workshop fabricaram todos os elementos necessários à ocupação, que seguiu uma diretriz básica de setorização para traçar possíveis utilizações, tais como local de armazenagem de chapas de madeira, espaço de trabalho, palestra e dimensionamento de mobiliário. Ao final da mostra, entregou-se os mobiliários para seus respectivos autores (Figura 8). 
Uma máquina de corte $\mathrm{CNC}$ foi instalada no local durante todo o período de funcionamento do evento, transformando o espaço em um verdadeiro makerspace. Foi proposto um espaço para abrigar a CNC com o intuito de proporcionar segurança aos visitantes, isolando ruídos e resíduos quando a fresadora estivesse ligada. A execução da estrutura do "aquário" em Madeira Laminada Colada justificou-se devido ao peso, que não deveria sobrecarregar o assoalho de madeira existente, além da rapidez de montagem a partir de elementos modulares industrializados.

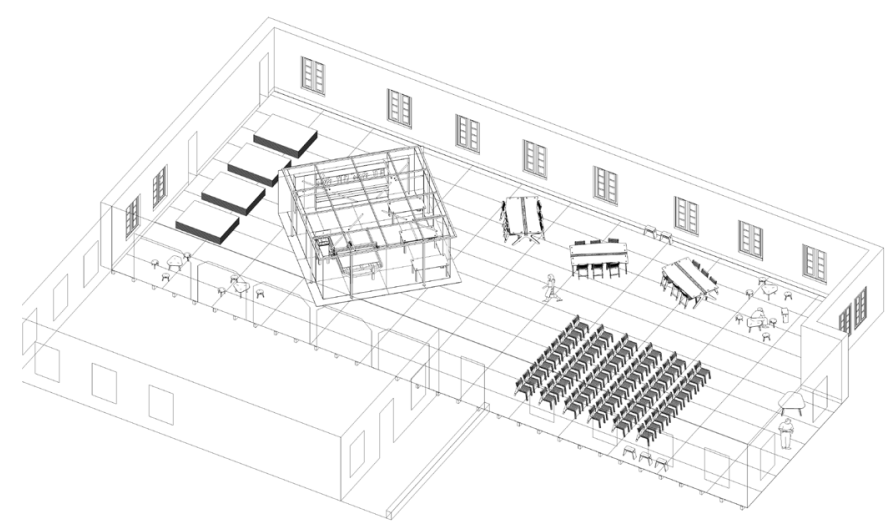

Figura 8 | GUAJA Sapucaí. Diretriz de setorização básica.

Fonte: Desenhos do autor 
Ao longo dos quatro dias de trabalho, o conteúdo programático da oficina procurou explorar, primeiramente, o panorama do Movimento Maker e do Open design. Discutiu-se cases e projetos análogos, encaixes, novas tecnologias de corte e reprodução 3D, o funcionamento de uma $\mathrm{CNC}$ e os modos de comunicação com a máquina.

Após esse momento inicial, os participantes aprenderam, na prática, sobre sistemas de fixação, cortes, tipos de materiais, fresas e espessuras das ferramentas - todo esse processo auxiliou o desenvolvimento e a fabricação dos projetos, que deveriam se adaptar à área máxima de meia chapa de compensado de $110 \times 160 \mathrm{~cm}$. No entanto, demandou-se uma superfície maior para a fabricação de alguns projetos, tais como mesas de trabalho e reunião, e, nesses casos, organizaram-se duplas que se serviram de uma chapa inteira $(220 \times 160 \mathrm{~cm})$.

Fez-se o uso de diferentes ferramentas complementares para cada etapa das atividades realizadas:

_Computadores Portáteis: O uso de laptops em todos segmentos de atuação profissional é amplamente difundido devido à sua praticidade. Dado às condições rudimentares em que o espaço se encontrava antes da ocupação, a ferramenta foi essencial para criação dos arquivos e discussão das propostas; 
_Lixadeira de cinta para dar desbaste inicial e realizar remoção de rebarbas das peças (lixa com grão 80);

_Lixadeira roto orbital para acabamento intermediário (grãos 80 a 220);

_Lixadeiras orbitais para realizar acabamento fino (grãos 150 a 600$)$;

_Parafusadeira elétrica para furação e aparafusamento de peças;

_Grampos de aperto rápido e grampos tipo sargento para realizar colagem das peças;

_Serra "tico-tico", formão e limas para ajuste das peças em que os encaixes ficam muito justos ou quando ocorre algum erro de projeto e é necessária uma intervenção manual.

Vale ressaltar que a disposição das peças na chapa de compensado, ou nesting (Figura 9), é de grande importância, uma vez que sua resolução se relaciona diretamente com aspectos de sustentabilidade do projeto, custos e resíduos. Ao se organizar as peças que compõem o projeto, tolerâncias dimensionais são previstas para ajustes de escala ou distorções da espessura da chapa. O espaçamento entre as peças resulta da geometria do tipo de fresa que é utiliza- 
da na trajetória de corte da CNC.

\section{Lição do workshop}

Busca-se contribuir para o surgimento de um ambiente de reflexão e aprimoramento por meio de iniciativas como a do Laboratório Efêmero. Práticas colaborativas, abertas e que visam à experimentação prática são tentativas de conectar sistemas isolados que já tendem a se conectar.

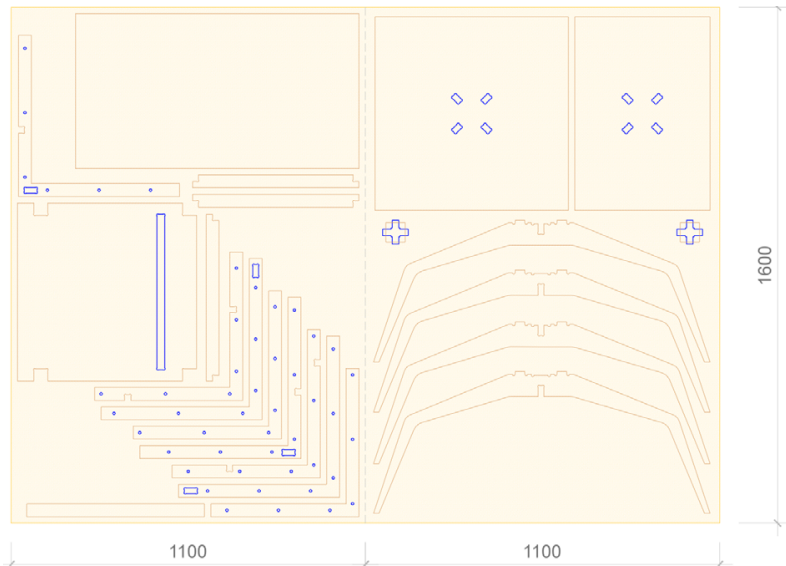

Figura 9 | Nesting "Poltrona Zero-Um" e "Mesa Volo". Fonte: Elaborado pelo do autor a partir de acervo do workshop Laboratório Efêmero. 


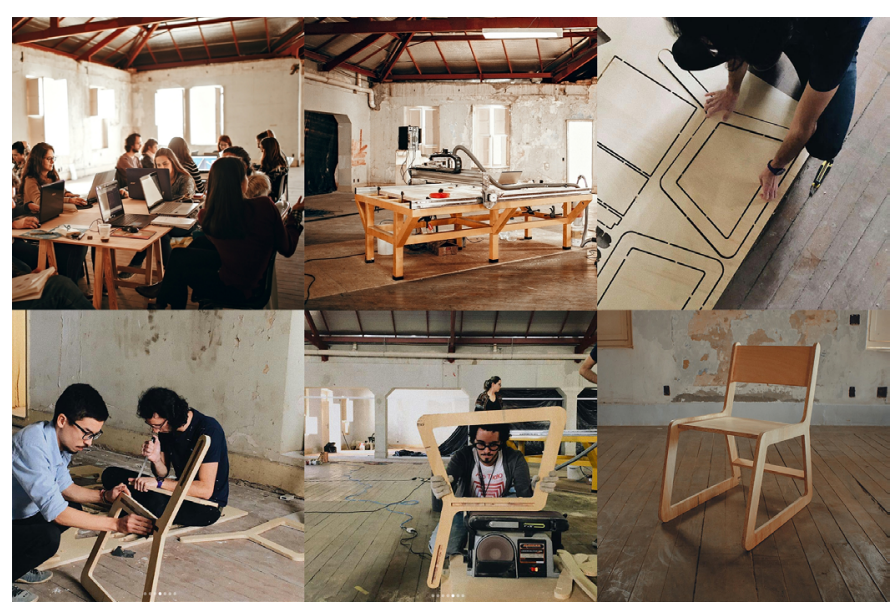

Figura 10 | Etapas do conteúdo programático do workshop: do projeto à execução da "Cadeira B" (desenhada por Bertrand Araújo).

Fonte: Acervo do workshop Laboratório Efêmero 



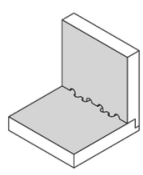

a
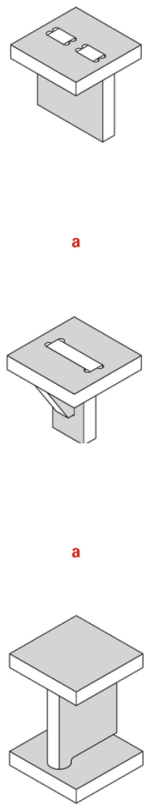

(a) montagem

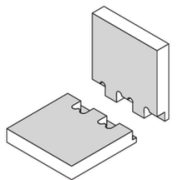

b
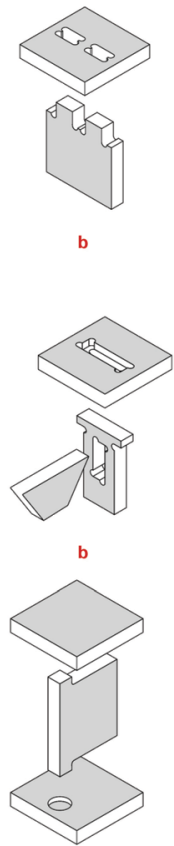

(b) peças desassociadas

\section{Encaixe CegoTipo Dedos}

Um encaixe oculto em que 0 resultado final visível é reduzido

Encaixe Espiga Trespasse Dedos

Uma articulaçāo permanente simples mas forte usando dentes e cortes. Pode ser escondido com rebaixos e redução da altura dos dentes.

\section{Encaixe em Cunha}

Um encaixe que cria tensāo ao ser travada com uma cunha inserida através de um buraco.

A cunha pode sofrer fadiga ao longo do tempo se o mobiliário for regularmente montado / desmontado

\section{Encaixe Dobradiça}

Uma soluçẫo de dobradiça CNC simples na qual os dentes quadrados de uma peça rodam dentro de rebaixos circulares da outra.

Figura 12 |Tipos de encaixes.

Fonte: Elaborado pelo autor a partir de Opendesk (2017) 

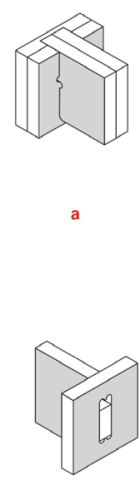

a

242
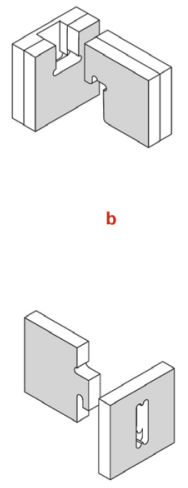

b

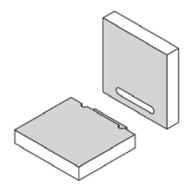

b

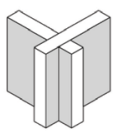

(a) montagem

\section{Encaixe Viga}

Um encaixe usado para montagens de vigas em montantes verticais como, por exemplo, uma perna de mesa.

\section{Encaixe Gancho}

Um encaixe frequentemente usado para montagens de vigas

em montantes verticais

\section{Encaixe Escondido / Espiga}

Um encaixe usado para junçăo de 90 graus entre peças

\section{Encaixe sobreposto}

Uma soluçāo de encaixe simples para peças que se encontram em um ângulo reto

Figura 13 | Tipos de encaixes.

Fonte: Elaborado pelo autor a partir de Opendesk (2017) 

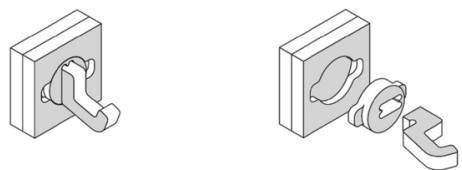

Encaixe

Fechadura / Chave
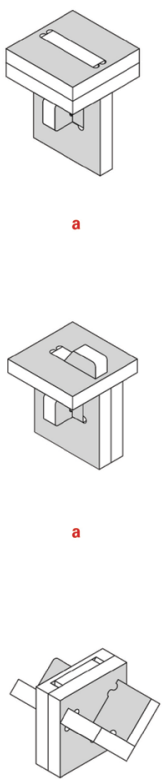

(a) montagem
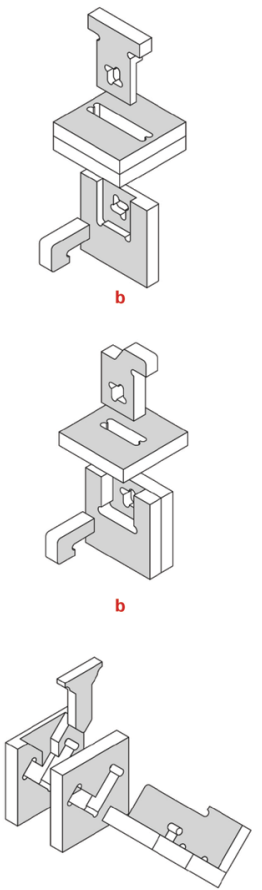

(b) peças desassociadas
Encaixe

Grampo de Travamento " $T$ "

Encaixe ideal para travar peças

Encaixe

\section{Grampo de Travamento " $\mathrm{E}$}

Encaixe ideal para travar peças que são regularmente montadas esmontadas

Encaixe

Grampo de Travamento "V"

Encaixe de travamento oculto

Figura 14 | Tipos de encaixes.

Fonte: Elaborado pelo autor a partir de Opendesk (2017) 


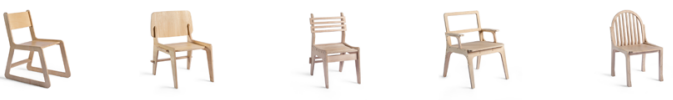

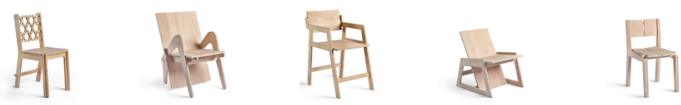

的泉最前步

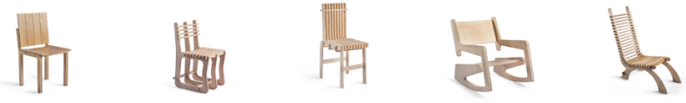

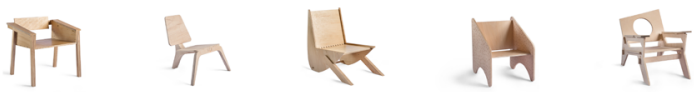

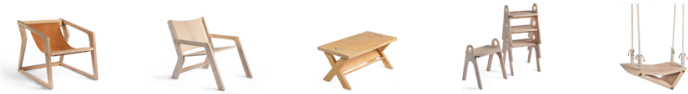

244

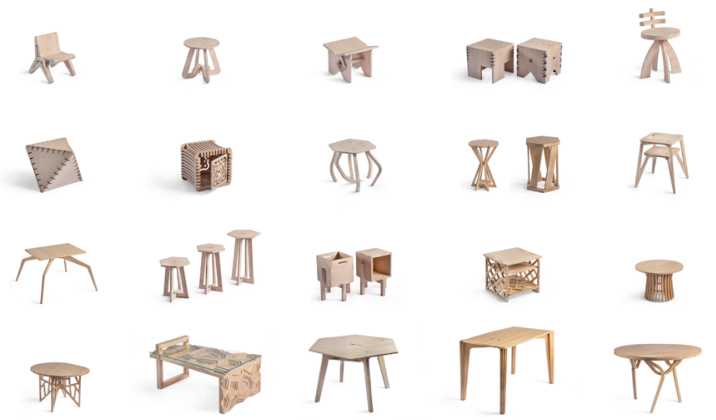

Figura 15 | Protótipos desenvolvidos e fabricados pelos participantes do workshop Laboratório Efêmero.

Fonte: Elaborado pelo autor a partir de acervo do workshop Laboratório Efêmero. 
Essas experiências visam, além do desenvolvimento tecnológico, resgatar o foco no indivíduo e suas diversas possibilidades de relações, seja com o fazer, com os outros parceiros do trabalho ou com a inovação, por exemplo. Pretende-se, ao final do processo, alcançar sustentabilidade social, ecológica e financeira, "além de uma reaproximação entre corpo e mente, atitude empreendedora e criação de novos valores" (NEVES, 2014, p.10).

Ao fabricarem seus mobiliários, sob o conceito de protótipo, os participantes do workshop lidaram com a possibilidade de errar e de ajustar como parte do processo do projeto. Considera-se a experiência de grande valor, uma vez que, devido à agilidade da execução dos protótipos, foi possível aproximar a investigação da forma por meio do desenho e de modelos tridimensionais com a construção de fato. Por fim, expôs-se os registros dos cortes nas paredes da ocupação a fim de, didaticamente, representar a origem de todo mobiliário que ocupou o espaço (Figura 16). 


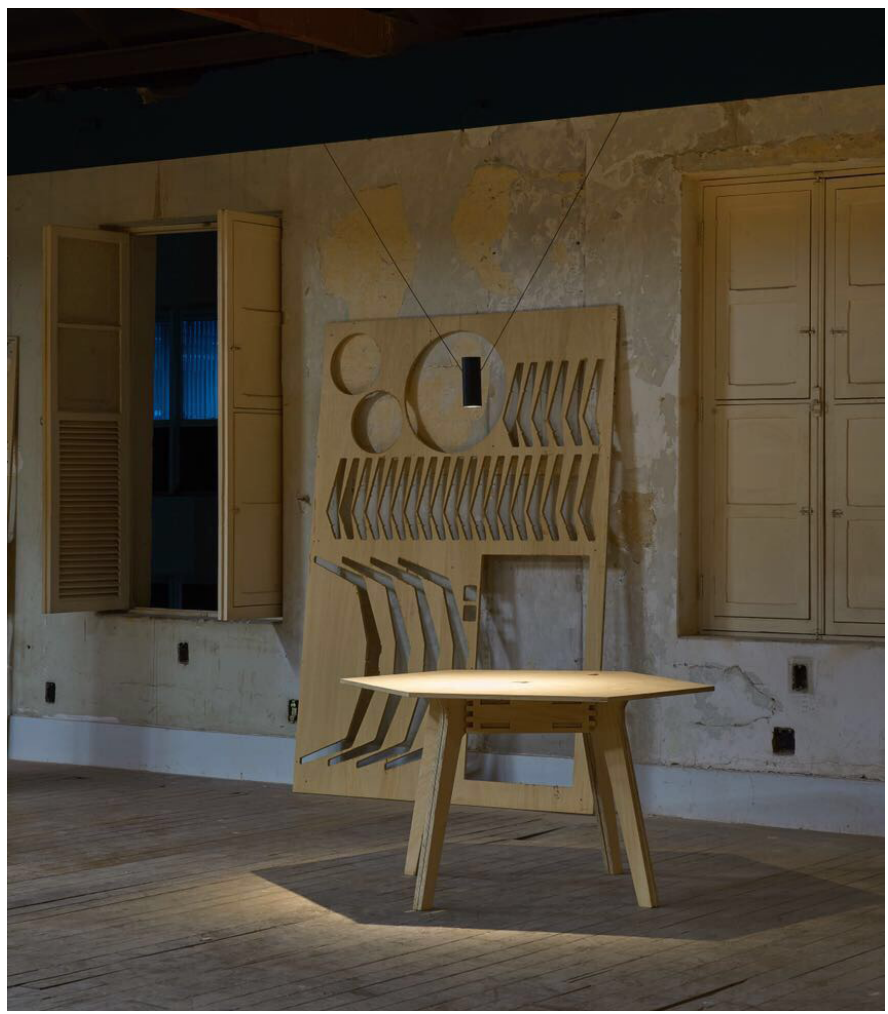

Figura 16 | Quadro-registro de corte da CNC Fonte: Jomar Bragança (2017) 


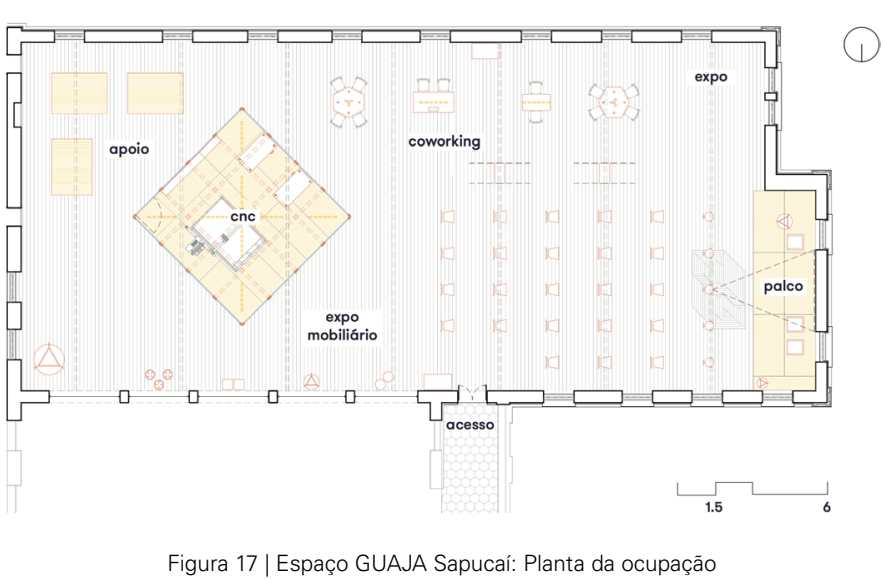




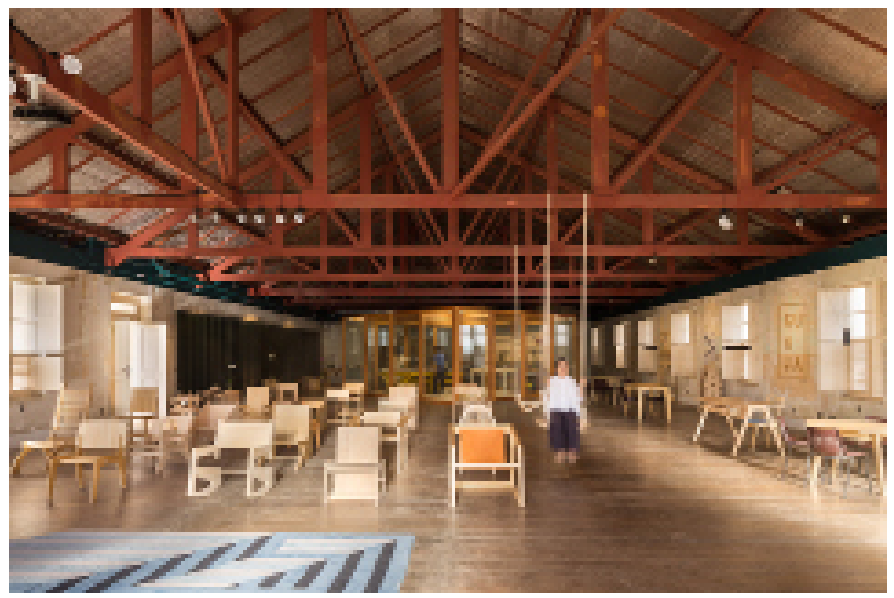

Figura 19 | Espaço GUAJA Sapucaí

Fonte: Gabriel Castro (2017)
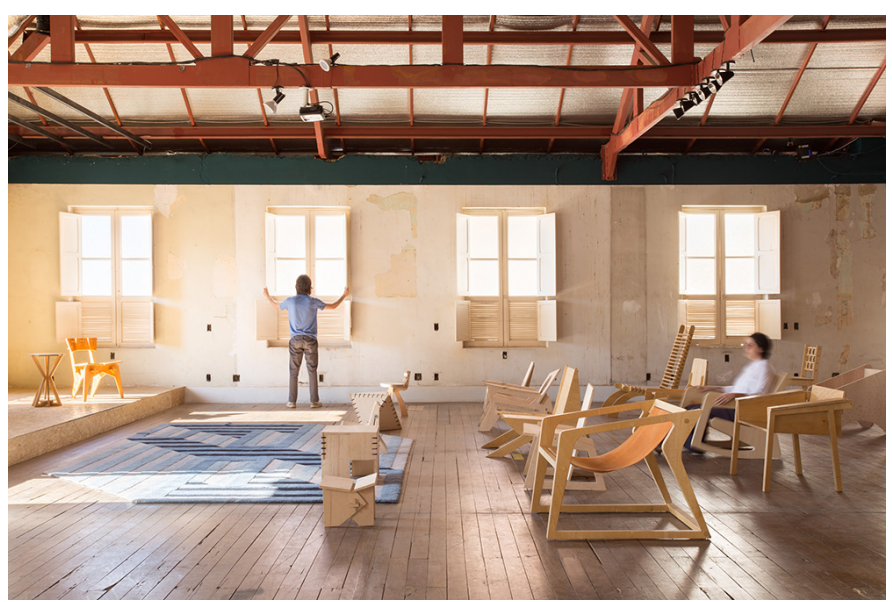

Figura 20 | Espaço GUAJA Sapucaí

Fonte: Gabriel Castro (2017) 


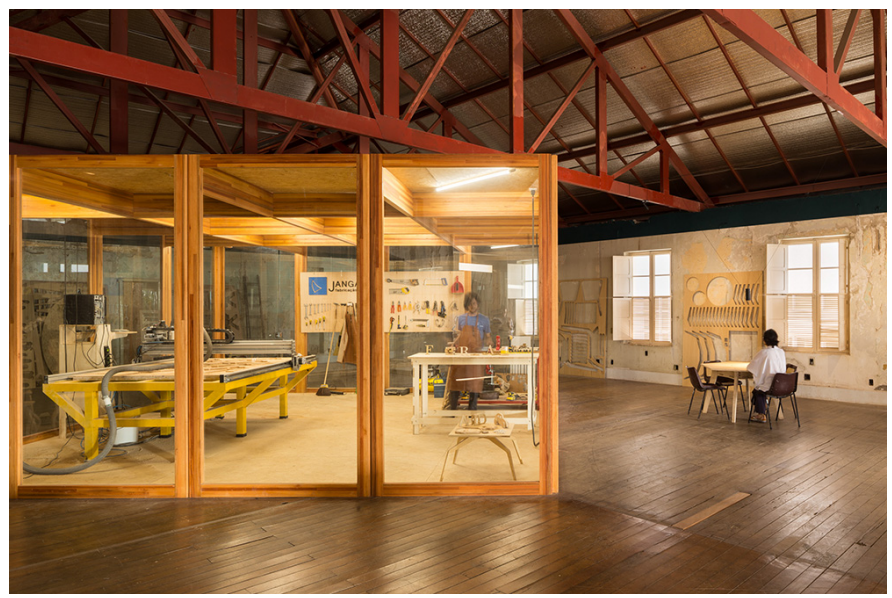

Figura 21 | Espaço GUAJA Sapucaí Fonte: Gabriel Castro (2017)

\section{Referências}

ARCIPRESTE, C. M. Entre o discurso e o fazer arquitetônico: reflexões sobre o ensino de arquitetura e urbanismo e seus referenciais a partir do Trabalho Final de Graduação. 2012. 287f. Tese (Doutorado) Faculdade de Arquitetura e Urbanismo da Universidade de São Paulo, São Paulo.

ARTEK. Enzo Mari for Artek: Homage to Autoprogettazione, 3 abr. 2012. Disponível em: <https://vimeo.com/39684024>. Acesso em: 10 out. 2017.

LAWSON, Bryan. Como arquitetos e designers pensam. São Paulo: Oficina de textos, 2011. 296 p. 
LEITE, M. A. D. F. D. A aprendizagem tecnológica do arquiteto. 2005. 366f. Tese (Doutorado) - Faculdade de Arquitetura e Urbanismo da Universidade de São Paulo, São Paulo.

MARI, E. Autoprogettazione? Mantova: Edizioni Corraini, 2002. 64 p.

NEVES, H. Maker innovation: do open design e fab labs às estratégias insipiradas no movimento maker. 2014. 261f. Tese (Doutorado) - Faculdade de Arquitetura e Urbanismo da Universidade de São Paulo, São Paulo.

OPENDESK. Opendesk Blog. CNC machines and common cut types, 22 set. 2017. Disponível em: <https://www.opendesk.cc/blog/ cnc-machines-and-common-cut-types>. Acesso em: 6 out. 2017.

OPENDESK. Opendesk Blog. Digital woodworking- remastering traditional joints, 26 set. 2017. Disponível em: <https://www.opendesk. cc/blog/digitally-remastered-joinery>. Acesso em: 6 out. 2017.

OPENDESK. Opendesk Blog. The Vitra Schaudepot, 12 jul. 2017. Disponível em: <https://www.opendesk.cc/blog/opendesk-x-the-vitra-schaudepot>. Acesso em: 10 nov. 2017.

OPENDESK. Opendesk Open Making. Designer Collaboration, 2017. Disponível em: <www.opendesk.cc/open-making/designer-collaboration>. Acesso em: 6 out. 2017.

STUDIO DLUX. Página da loja no Instagram. Disponível em: <https:// www.instagram.com/studiodlux/>. Acesso em: 05 fev. 2018.

WORLEY, J. Opendesk - Design for Open Making and CNC machines, 2 out. 2017. Disponível em: <https://www.opendesk.cc/blog/ design-for-open-making-and-cnc-milling-machines >. Acesso em: 6 Outubro 2017. 